\title{
Effect of Mentorship Programmes on the Performance of Students in Secondary Schools in Mbooni East District, Makueni County-Kenya
}

\author{
Betty Wanjiru Karanja \\ School of Education, Mount Kenya University \\ Bettykaranja83@gamail.com \\ John Muthee Gikungu \\ School of Education, Mount Kenya University
}

Doi:10.5901/mjss.2014.v5n5p

\begin{abstract}
A study by Slicker and Palmer (1993) showed that effectively mentored students tended to have higher academic achievement and had other characteristics like self-concept. Academic achievement and dropout rates can be influenced by mentoring efforts. Mentored students tent to behave positively and more responsively, they are more disciplined than none mentored ones. Yet in Mbooni East District secondary school students have continued to perform poorly and have been found to be indisciplined. Still many students are performing unsatisfactorily despite most of them having been admitted to secondary school with high marks in KCPE and they later perform poorly in the KCSE there is need therefore to find out what goes on in the life of the same person who performed well in one stage and badly in a period of four or so years. Do the Schools have mentorship programmes? How are they organised? How they are implemented?
\end{abstract}

Keywords: Mentorship, Teachers, Students, Schools, Performance

\section{Background}

Mentoring has existed since ancient Greek times in Europe. In the 1970's it spread to the united states of America and was mainly used in training contexts. Edgar Schein carried out a research in 1978 to confirm what Daniel Levinson had studied in 1970, where he had led some women and African Americans to question whether the classic 'white male organization was welcome for people who were newcomers. The two -Schein and Levinson came up with a multiple mentoring technique described as mosaic mentoring which is based on the concept that almost everyone can perform one or another function well for someone else, and also can learn along and from someone else. In mentoring, newcomers are paired with more experienced people (mentors) in order to obtain information, good examples and employees as they advance. It is claimed that new employees who are paired with a mentor are twice likely to remain in their job than those who do not receive mentorship (Schein Edgah H. 1978) Many countries especially in the developed world have come up with institutions and programmes for preparation and development of young students.

In America, for example, George W. Bush helped establish 'America's Promise', that is, a National Mentoring Programme to help remedy for social problems associated with the youth. According to Dondero (1997); Tierney and Grossman (2000) educators are having high hopes for mentorship support for students. They see it as secondary sphere of activity outside the family. In African set-up, models or mentors were adults who walked along side younger people and mentored them to become what society viewed as well-adjusted capable individuals.

The mentorship's programmes in African setting served psychosocial, spiritual, professional and educational goals. (Maloner, 2011). In many secondary and post-secondary schools, mentorship programmes are offered to support students in programme completion, confidence building and transitioning to further education or the workforce peer mentoring in secondary school are done in aid of younger students from primary school to secondary school. They are mainly assisted with study skills, peer pressure such as pressure to use drugs or have sex, issues with attendance and behaviour and typical family problems (Maloner, 2011). Mentorship in secondary schools in Kenya is critical to the attainment of educational goals. This is especially true regarding the role played by mentorship in which a more experienced member of the organization i.e. school maintains a relationship with a less experienced, often new member to the organization and provides information support and guidance so as to enhance the less experienced members chances of success in the organization and beyond. The success of these new members in the school can be achieved 
mainly if they are specifically prepared for the new environment and how welcoming the school is.

In Mbooni East District for example, most students who were admitted to form one with very high marks in K.C.P.E, ended up performing poorly in the K.C.S.E, In secondary schools when students join form one or through a transfer from another secondary school, someone will try to orient them whether they have been asked to do so or not. Students joining form one are usually in their early stages of adolescence, where if not well guided the new environment could lead to them engaging in antisocial behaviors such as drug use and abuse and failure to attend classes One challenge is whether those students actually meet the right people to guide them in the right way. Increasing evidence show that students throughout their -stages of learning can benefit from a mentoring system in which a seasoned mentor or protégés place theory and practice in the context of experience (Maloner. 2011). The greatest challenge here is if the mentorship programmes actually are there formally or informally and if they are there, who mentors the student. If the mentorship programmes are formalized structures, then are the results desirable? The effect of mentorship programmes on the performance of students in secondary schools in Mbooni East District was the major concern that the study sought to investigate.

\section{Theoretical Frame Work}

The social learning theory by Albert Bandura suggests that aggression is learnt through a process called behaviour modelling. According to him individuals, children learn aggressive responses from, observing others, personally or through media and environment. One of the results of these is building self esteem. Observation-learning also imitation or modelling occurs when individuals observe and imitate others behaviour. In this study, the learner observes and imitates the behaviour of the mentor as they expect to receive positive reinforcement for modelled behaviour. Conceptually, when mentorship programmes are put in place the student's learn or is integrated into the school culture. They learn about themselves which help to boost self esteem. The discipline is enhanced and goals are easily realized. Due to these, academic performance of students is improved and students develop positive attitude towards performance. This is because according to Social Learning Theory of Albert Bandura, a student with negative or criminal behaviour will learn and change according to the mentor through socialization.

\section{Results/Outcome of Mentorship Programmes}

The earliest study was by Slicker and Palmer (1993) who studied students who were in a racially and social economically diverse district. At first their findings sound no significant difference between mentored students and none mentored one. However, a review showed variations in the quality of mentoring that students received. This study showed that mentored students tended towards lower dropout rates than in effectively mentored students and that their academic grades were higher. It also showed that mentoring can greatly influence self concept.

Another recent study by Thompson and Kelly -Vance (2001) found that mentored boys made significantly higher academic gains when mentored than none mentored boys. Research by Beier R. (2000) supports the use of mentors as a strategy to reduce certain adolescent risk taking behaviour. In his study the researcher found out that adolescent with mentors were significantly less likely to engage in risk behaviours such as carrying a weapon, using illicit drugs, smoking, engaging in premature sex and other anti-social behaviours.

Mentored students have also been reported to feel more confident about school performance and their family relationship improved. The positive effect of mentoring can also be seen on student's sense of self-efficacy in their hopes for the future. Economically disadvantaged students in a formal mentoring programme demonstrated improved educational and occupational aspirations which have been linked to lower probability of dropping out of school. Mentoring may not always be successful sometimes if adolescents have identified with their mentor and have begun to value the relationship they are up to feel profound disappointment if the relationship does not progress. Feelings of rejection and disappointment in turn can lead to a host of negative emotional behaviour and academic outcome.

Dondero (1997) in his study concluded that, mentoring helps new students adapt to a new academic environment faster. The relationships between, the mentor and mentee gives the mentee a sense of being connected to the community where they may otherwise feel lost. Mentors may be chosen because they are academically successful and because they may posse s good communication, social and leadership skills. As a consequence mentors serve as positions role models for the students, guiding them towards academic and social success. Mentors provide support: advice encouragement and even friendship to students. Mentors also stand to benefit from the mentor/mentee relationship. They develop friendship through their participation in mentoring programs and usually derive satisfaction from helping younger students in shaping their life in a positive way. 
For the past two decades, Kenya has had a history of inter-ethnic violence; this has not been without leaving our youth and especially the secondary school students, who are often in boarding schools to have adaptive problems when in school. This necessitated for membership for these young beings in the Rift Valley Province for example, where such violence is concurrent. The Youth Leadership Development for Reform Project was implemented by the Centre for Transformational Leadership (CTL) and the Centre for Creative Leadership (CCL) whose objective was to help young people in the Rift Valley have a greater appreciation for themselves and others. CTL used mainly Public High Schools because they draw their population from poor and middle income families. The key activity was youth mentorship training to help students who were mainly victims of displacement. It is generally believed that students learn best when they like the teacher. It is therefore a fact that when a teacher or a mentor introduces something which he positively talks about the mentee will take it positively e.g. Hendrickson (1997) in his study found out that attitude toward physics subject by most students has an impact on their performance. (Lupdag 1989) has emphasized that mentoring a student to like a subject makes him enthusiastic to learn it that the one is not mentored.

Certain learner attitudes have an impact in whatever learning experiences a student's personality includes his set of beliefs and attitudes that characteristic his adaptation to a situation such as learning. (Cheng 2004). This recent study reveals that a student one positively mentored can develop a liking for a subject and subsequently perform well in it. It is therefore common knowledge that if students needs to perform well both academically and behaviour wise the schools need to put in place mentorship programmes.

Mentoring caught public's attention in 1980. When it shifted focus to an educational setting. Study shows that Eugene Lang, after speaking to students, the event sent off a new wave of mentoring in public schools mainly to combat high dropout rates and encourage retention in secondary school. Mentoring programs are also found to encourage and direct students on career options. Mentors are seen as serving as role models and are implicitly charged with helping students navigate the school system According to Sharon Merriam. One of the more intriguing topics to have emerged in several fields within the last few years is that of mentoring. Mentoring is said to be the key to career and academic success as well as a necessary ingredient in psycho-social development. It is very well known that successful people had mentors: there is the issue of, who should be a mentor?

There is no clear definition that exists of who a mentor should be in an academic setting. A study by Mendoza and Samuel suggest that programs utilization of faculty members or mentors does have a positive impact on student retention and sustainability. It showed that $94 \%$ of those mentored finished education courses. According to De Jesus the mentor's predisposition to the student can be key to whether the program works or not. We must be certain that mentoring assists young students in achieving academic or career goals if mentoring works at all, we must learn under what circumstances and in what settings it is most effective. Mentoring in educational setting has been widespread throughout the 1980's and programs continue to increase. The empirical question here is. What is mentoring all about; does it work, if so far whom does it work best and in what settings?

\section{Relationship between Mentorship and Academic Performance}

"Not everyone so easily and without inspiration express their brilliance, not everyone's gifted the same way. Some people pick up quite easily in life, some are a bit slow before they gain momentum and still others have no idea if they were born to shine in this world. It takes a visionary parent, teachers or a mentor to jump start some youngsters' (Pepe M. 2010),

A story is told of "Alexander the Great' who became a student of the Greek philosopher Aristotle at age thirteen. Under the mentorship of Aristotle he gained great knowledge in philosophy medicine and Science. At age twenty, he took the throne of his father King Philip when he (his father) was assassinated. By looking at the life of Alexander the great, one can see the influence of mentorship. His mentor Aristotle who had cultivated in him a lot of interest in reading and learning.

Pepe M. (2010) adds that there is greatness within each one of us simply waiting to be triggered in order to blossom, 'the human spirit is not a vessel to be filled but a fire to be lightened'. Mentors play this great part of igniting the potential in young beings that have not yet discovered these potential. Nelson Mandela in his inaugural speech in 1994. Said, "'we were born to make manifest the glory of God that is within us. It is not just in some of us it is in everyone and as we let our own light shine, we unconsciously give other people permission to do the same, as we are liberated from our own fear, our presence automatically liberates others." In the corporate (business world) mentorship has started to be embraced and is bginning to catch up on developing countries.

According to Daily Nation, Monday December 12, 2011. small and medium enterprises, that have previously faced challenges of inadequate technical and business can now have these comprehensively addressed, thanks to mentorship programmes that has been started as a field of study at Inorero University. It further says that, for mentorship to be 
effective, the mentor and mentee need to agree and document specific goals and targets and learn and understand each other and clearly establish their roles and commitment. The mentor needs to view his role as an advisor, encourager, analyzer and never a decision maker. On the other hand, the mentee must be open and be ready to make and act on decision taken.

In mentoring, the mentee needs to be teachable and value mentorship. In this he is able to know the world in which he is coming from, the world in which he is living and the world in which he is going to in the future. Students' self esteem and ego, can be raised and even built through mentorship, even the ones who do not show any powers and charisma, in anything in life, there is still a spark of greatness in them, which only need to be provoked positively, by mentoring.

Most students join secondary schools with low points, and consciously or unconsciously are programmed, when it comes to performance, as average students, making them finally low performers. It is important to know that butterflies are made from moths and even the ugly, hustling, style-less caterpillar, which no one likes near them, carries within itself, the potential of becoming a butterfly. So even the so called poor or average performer can come around and be great performers through mentorship. Since even tides can turn with mentorship, every student can change their identity and profile; all they need are wings to fly i.e. mentorship.

\section{Situation of Mentorship Programmes in Secondary Schools}

Mentoring of new students into secondary schools is done in some schools in Kenya. However, there are only a few known schools like The Kenya High School where mentorship is a formalized and well-structured programme. Even in this there are problems especially when an aged form one student is given a mentor who is several years younger in upper classes. In other schools where mentorship is done, it can be so unstructured, that the schools are not in control such that students determine their own way of transferring experiences to new students. The kind of mentorship a student gets in such situations could have negative effects or results like, being introduced to drug, homosexuality, and lesbianism. Some could have positive effect like being introduced to reading or sports culture. In Mbooni East, there are no known cases of mentorship programmes that exist, if there are there then, they could be taking place informally. The fact that lack of mentorship can lead to students' discipline being poor who can subsequently lead to engagement in antisocial behaviours is a big issues affecting most secondary schools students. This has led to many school riots in the District culminating to mass destruction of school. Property, coupled with this, the students end up performing poorly in their internal examinations and also external ones, that is, KCSE. The need for mentorship is more evident since new students need to acquaint themselves to the culture of the new environment, that is the school and all mentorship's do not always translate to positive behaviour. In absence of formalized mentorship programmes any student becomes the main source of transferring new experiences.

\section{Finding and Discussion}

The study sought to answer the research questions as, how many secondary schools in Mbooni East have established mentorship programmes? What is the nature of these mentorship programmes, what forms do they take? Are they officially structural or not? To what extent does the school administration influence the mentorship programmes? And what are the results of mentorship programmes on performance of secondary school students in Mbooni East District?

\subsection{Response rate}

The response rate was established from schools that participated and those that did not participate in the study. Responded

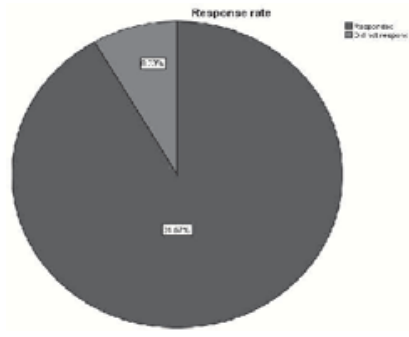

Figure 4.1: Response rate 
The study targeted 12 schools within which 10 students, guidance and counselling teacher and a principal were drawn. Out of the 12 schools 11 participated in the study while 1 did not. The response rate for the study was $91.67 \%$ representing high ability of the study finding to adequately address the study objectives and answer the research questions. Demographic information sought to provide information about type of schools surveys, respondent's gender, experience of school heads and guidance and counselling teachers, class for different students and the year of admission. The findings on the demographic information were presented on table 4.1 below.

Table 4. 1: School principal

\begin{tabular}{|c|c|c|c|}
\hline \multicolumn{2}{|c|}{ School principals } & Frequency & Percentage \\
\hline Respondents Demographic information & Boys boarding & 2 & 18.2 \\
\hline \multirow{2}{*}{ Type of school } & Girls boarding & 3 & 27.3 \\
\hline \multirow{5}{*}{ Gender } & Mixed boarding & 1 & 9.1 \\
& Mixed day and boarding & 1 & 9.1 \\
& Mixed day & 4 & 36.4 \\
& Total & 11 & 100.0 \\
\hline & male & & \\
& female & 8 & 80.0 \\
& & 2 & 20.0 \\
& & & \\
\hline \multirow{5}{*}{ Duration as a principal } & & 7 & 70.0 \\
& & 1 & 10.0 \\
& $1-5$ yrs & 2 & 20.0 \\
& $11-15$ yrs & 0 & 0.0 \\
& $16-20$ yrs & 0 & 0.0 \\
\hline & 21 and above & 10 & 100.0 \\
\hline
\end{tabular}

\subsection{Guidance and counselling teachers}

All the study respondents were drawn from 2 boy's boarding secondary schools epresenting 18.2\%, 3 girls boarding secondary schools forming 27.3\%, 1 mixed boarding and mixed day and boarding forming 9.15 and 4 mixed day boarding schools forming the majority $36.4 \%$ of respondents. Majority of respondents for both $\mathrm{G} \& \mathrm{C}$ teachers as well as school principals were male with females forming the minority group. Majority of guidance and counselling teachers demonstrated experience between 1-5 years with minority demonstrating 15-20 years of experience. Likewise, majority of school principals (70\%) indicated an experience of 1-5 years with minority having 6-10 years in their respective schools. The gender distribution of students indicated higher percentage for girls (59.7\%) with boys being $40.3 \%$. Majority (32.6\%) of students who participated in the study were in form three with minority (14.7\%) being in form 1. Students admitted in the school in the year $201032.6 \%$ formed majority while those admitted in the year 2012 formed the minority (16.3\%) in the study.

\subsection{Mentorship programmes}

The mentorship programmes on performance of students was established through systematic examination based on the research objectives mentioned at the introductory part of this chapter. The findings have been broken down based on each research objectives and discussions provided in order to draw conclusions. The study established the existence of mentorship programmes from the guidance counselling teachers as well as from the students. Response on the finding was reflected on figure 4.3 and figure 4.4 below.

From the response of guidance and counselling teachers, it was evident that majority of school in Mbooni east district had mentorship programmes. Asked to confirm whether or not their schools had mentorship programmes, $90.91 \%$ of the respondents confirmed that it was there while $9.091 \%$ did not confirm that. All G \& C teachers who participated in the study indicated that they were participants of mentorship programs. There was also evidence of mentorship among students as evidences by responses on the criteria for allocation of mentors. There was no conclusive evidence from the results that the school teamed up with the community to enhance mentorship. 


\subsection{Service provided by $\mathrm{G} \&$ C Teachers}

Apart from guidance and counselling, $G$ \& $C$ teachers were asked to indicate the other service that they provided for their schools. This was in pursuit of establishing the link between mentorship programme and ability to influence students academic performance. The findings in figure 4.3 above indicate that $G \& C$ teachers provided community service (9.091\%), coaching (27.27\%) and spiritual and life skills education (63.64\%). Owing to the finding that G \& C teachers were involved in mentorship programmes, there is therefore a likelihood that these are the most common skills that they would transfer to their mentee and the same skills likely to affect the mentees (students) academic performance.

\subsection{Problems presented to $\mathrm{G} \& \mathrm{C}$ teachers}

Different problems were presented to $G$ and $C$ teachers on equal measures as established from the study findings. Among the problems that students presented to $G$ \& $C$ teachers included; boy- girl relationship (18.18\%), student- parent and teacher relationship (18.18\%), career choice (18.18\%), academic issues and career choices (18.18\%), self-esteem (18.18\%) and drug use and abuse $9.091 \%$. From the finding it is evident that guidance on career choices and academic issues is among the many problems that students in secondary schools would wish to be mentored on. This would therefore mean the effective mentorship programme is likely to affect the academic performance of students.

\subsection{Influence of administration of secondary schools on mentorship programmes}

The influence of administration on mentorship programme was established through establishing existence of various parameters that acted as indicators. $G \& C$ teachers provided information on existence of any assistance from for $G$ \& $C$ programmes and the kind of assistance provided, students providedinformation of existence of any help in terms of selfunderstanding provided by the school administration while school principals indicate their level of awareness on $G \& C$ programmes, the nature (structure of the programme, their supervision roles in the mentorship programme and availability of goals for the mentorship programmes.

\subsection{Assistance provided by school administration}

The study found out that the school administration assisted G \& C programmes in many ways. This included; provision of resources and financial aid (27.27\%) , mobilizing of students 18.18\%, taking teacher and peer counsellors for seminary's $18.18 \%$, and inviting external counsellors $36.36 \%$. The major influence was however seen in the provision of resources and financial AID.

\subsection{Influence of administration on helping students know themselves}

Another evidence of school administration was found in the confirmation by majority (89.84\%) respondents confirmation that the school administration helped students themselves. This could mean that the administration was not only providing financial aid , but also facilitated success of students mentorship in schools .

Different ways in which the school administration was involved in mentorship programmes included awareness of mentorship programmes in the schools, involvement in the initiation of mentorship programme, creation of a structured mentorship programmes in the schools, assistances issues arising from mentorship programmes (57.1\%) provision of supervision roles (89.9\%), assisting in determining the criteria used to allocate mentor/ mentees, establishing goals for mentorship programmes and having meeting with students to ensure the goals are met. It was also noted that evaluation of mentorship programmes was through reports as established by $42.9 \%$ majority of respondents.

\subsection{Results of mentorship programs on academic performance}

The literature revealed that mentoring was an important component in education. Among the importance of mentorship as noted in the literature include An improved sense of health and well-being, an enhanced self-image and sense of selfworth, a sense of feeling valued and appreciated, a sense of feeling competent and accomplished, a sense of spiritual fulfilment, a feeling of having gained deeper insights into one's own childhood experiences, sense of feeling needed and a feeling of being respected by others for contributing to society in a very important way. The results of such benefits 
were expected to be reflected in the school's academic performance as established in the study. The findings on this establishment are reflected below.

\subsection{Solving problems}

Mentorship programmes in schools were found to help students formulate solutions to themselves as indicated by $10 \%$ of the respondents facilitate guidance and counselling among G \& C teachers (47\%) identify caused of problems (20\%) and facilitate discussion between students and teachers (30\%) This could imply that mentorship was important parameters in enhancing development of virtues favourable for academic performance among students. The results of mentorship programmes concurs with Slicker and Palmer (1993) observation that found significant difference between mentored students and none mentored ones. Several activities were found to be undertaken by mentors '/ mentees. This included, studying together as indicated by $15.6 \%$ of the respondents, sharing academic / family challenges as indicated by $55 \%$ of the respondents, advising each other as indicated by $24.6 \%$ of the respondents. It can therefore be concluded that mentorship involved not only sharing on academic issues but also personal issues that involved family matters.

\subsection{Results of mentorship programs}

The results of mentorship included harmonious relationships (16.7\%), better behaviour, 16.7\%, improved academic 50\%, and facilitating quick settling among students (16.7\%). From the results it can be noted that mentorship programmes led in improved academic performance as noted by $50 \%$ majority of respondents. Several activities were found to be undertaken by mentors " mentees. This included, studying together as indicated by $15.6 \%$ of the respondents, sharing academic / family challenges as indicated by $55 \%$ of the respondents, advising each other as indicated by $24.6 \%$ of the respondents. It can therefore be concluded that mentorship involved not only sharing on academic issues but also personal issues that involved family matters.

\section{Results of mentorship programs}

The results of mentorship included harmonious relationships (16.7\%), better behaviour, 16.7\%, improved academic 50\%, and facilitating quick settling among students (16.7\%). From the results it can be noted that mentorship programmes led in improved academic performance as noted by $50 \%$ majority of respondents. Results were presented and discussed below.

\subsection{Effect of mentorship programmes on academic performance}

Majority of students confirmed that mentorship programmes improved on their academic performances. From the study findings on table 4.7 above, it can be noted that $63.6 \%$ majority students say yes on the question of whether or not mentorship relationships affected academic performance. One would therefore conclude that mentorship was an important aspect in shaping the direction of academic performance of secondary schools in Mbooni East district.

\subsection{Academic parameters affected by mentoring}

Academic parameters affected by mentoring programmes included; improved grades (65.2\%), better behaviour among students $11.6 \%$, mental and physical morale $22.3 \%$ and increase morale $0.9 \%$. Majority of respondents indicated improved grades as the most popular academic parameter affected by mentoring programmes. This could therefore mean that mentorship programmes elicited strong relationship with academic performance. The finding concur with Dondero ( 1997 ) study that observed that , mentoring helps students adapt to new academic environment faster, through enhancing the relationship between the mentor and mentee.

\section{Conclusions}

Mentoring is an eminently practiced programme within secondary schools in Mbooni East district. There is however no evidence of formal structure in which the process is undertaken. This leaves many schools with no clear-cut guideline on how mentoring should be undertaken. As a result, most schools admit that mentoring programmes has been integrated within guidance and counselling department. Most $\mathrm{G} \& \mathrm{C}$ teachers are evidently in charge of mentorship and demonstrate 
high level of experience with at least majority having an experience between 1- 5 years. This could be a good demonstration of the level of knowledge about mentorship that teachers have. There is evidence of strong administrative support for mentorship programmes in secondary schools in Mbooni East district. Indicators of administrative support for $\mathrm{G} \& \mathrm{C}$ include provision of resources and financial aid, mobilizing of students, taking teacher and peer counsellors for seminary's, and inviting external counsellors, helping students realize themselves, initiation of mentorship programmes, creation of a structured mentorship programmes in the schools, assisting in issues arising from mentorship programmes, provision of supervision roles, assisting in determining the criteria used to allocate mentor/mentees, establishing goals for mentorship programmes, having meeting with students to ensure the goals are met and evaluation of mentorship programmes.

The results of mentorship included harmonious relationships, better behaviour improved academics and enhancing quick settling among students. Mentoring was found to be important components in education. Mentorship programmes in schools were found to help students formulate solutions to themselves, facilitate guidance and counselling among $G$ \& $\mathrm{C}$ teachers, identify caused of problems, and facilitate discussion between students and teachers. Such important virtues created through mentorship programmes could therefore have facilitate enhancement of academic performance among students. Other results of mentorship included studying together, sharing academic / family challenges and advising each other. It can therefore be concluded that mentorship involved not only sharing on academic issues but also personal issues that involved family matters.

Mentorship programmes elicited strong relationship with academic performance. Mentorship was an important aspect in shaping the direction of academic performance of secondary schools in Mbooni East district. Evidence from majority of students' respondents indicated that mentorship programmes improved on their academic performances through improved grades, better behaviour among students and mental and physical morale

\section{References}

Beier S. (2000). The Potential Role of an adult mentor in influencing high risk behaviour in adolescents. Archines.

Chen (2004). Physicals learning activities for fostering student's creativity. Daily Nation, Monday Dec, 12.2011

Dondero G.M (1997). Mentors. Beacons of hope Adolescence Fee R. (1999). The positive effect of mentoring economically disadvantages student professional school counselling.

Gay L.R. (1992). Educational Research, Competences for analysis and application. Ohio, Charles E meril pub. Co

Grossman J.B \& Tierney J.P (1998). Does Mentoring work? An impact study of the big brother \& Big brother \& sisters program.

Evaluation review.

Malone J.R (2011). Principal mentoring (retrieved) from w.w.w. eric. Com. 5th August 2011. Merrian - mentors and prosteges.

McMillan J.H (200). Essential Assessment concepts for teachers and

administration. Thousand Oaks CA, Corwin publishing.

Orodho J.A (2003). Elements of Education \& Social Science Research Methods: Maseno Kanezja.

Orodho J.A (2010). Techniques of writing research projects and reports. Nairobi Kanezja

Pepe M. (2010). Inspired for Greatness Nairobi. Flame Keepers. Schein, E.H. (1978). Career Dynamic; matching individual and organizational needs. Addison - Wesley.

Slicker E. Palmer (1993). Mentoring -at-risk high school students - evaluation of a school based programme. School counsellor.

Thompson L. (2001). The impact of mentoring on the academic achievement of at risk youth -children and youth services review. 